\title{
Application of a submersible spectrofluorometer for rapid monitoring of freshwater cyanobacterial blooms: a case study
}

\author{
Christophe Leboulanger ${ }^{1, *}$, Ursula Dorigo ${ }^{1}$, Stéphan Jacquet ${ }^{1}$, Brigitte Le Berre ${ }^{1}$, \\ Gérard Paolini ${ }^{2}$, Jean-François Humbert ${ }^{1}$
}

\author{
${ }^{1}$ Station INRA d'Hydrobiologie Lacustre, UMR CARRTEL, BP 511, 74203 Thonon les Bains cedex, France \\ ${ }^{2}$ Cellule Technique de l'Aquarium du Bourget, 200 av du Petit Port, 73100 Aix les Bains, France
}

\begin{abstract}
A recently available submersible fluorescent probe was configured and used to survey the vertical distribution of the deep-living toxic and filamentous cyanobacterium Planktothrix (Oscillatoria) rubescens among the autochthonous algal communities in Lake Bourget, France. This in situ measuring spectrofluorometer, which can be used to perform chlorophyll analysis and integrated algal class determination, provides a realistic estimation of the abundance and dynamics of the cyanobacterial population that is known to produce the hepatotoxic heptapeptides microcystin RR and LR. Data provided from in-line measurements using the probe and from P. rubescens cell counts obtained by discrete sampling were closely correlated $(\mathrm{r}=0.899, \mathrm{p}<0.01)$, as were in-line data and spectrophotometric total chlorophyll a measurements $(\mathrm{r}=0.775, \mathrm{p}<0.01)$. A survey conducted from December 1999 to May 2001 revealed that P. rubescens exhibits a deep maximum level (typically between 10 and $15 \mathrm{~m}$ ) in spring and summer (reaching concentrations of up to $20 \mu \mathrm{g}$ equivalent chl $a$ $\mathrm{l}^{-1}$, i.e. 27000 cells ml ${ }^{-1}$ ), whereas it spreads from the surface either to the top of the thermocline or to the bottom of the lake, in autumn and winter respectively. We propose that the probe could be used as a powerful tool for assaying the occurrence and dynamics of microalgal blooms, typically toxic cyanobacteria, that call for accurate and rapid monitoring to assess the health of the ecosystem and to alert the authorities about potential risks regarding pumping and use of the lake water for drinking-water production purposes.
\end{abstract}

KEY WORDS: Cyanobacteria $\cdot$ Fluorescence $\cdot$ Bloom $\cdot$ Monitoring $\cdot$ Water supply

\section{INTRODUCTION}

The quality of surface waters around the world is receiving increasing attention because, in the absence of strong policies and regulations, any overall degradation (either by anthropogenic chemicals or biochemicals, or by living organisms) precludes its long-term use. The threats of biological origin that have been identified to date include the occurrence of toxin-producing organisms (both microalgae and cyanobacteria), which can produce spectacular and/or dramatic events, such as

*Email: leboulan@thonon.inra.fr the contamination of seafood, diseases in fish and humans, or animal deaths (Mez et al. 1997, Falconer 1999). Recently, the World Health Organization (WHO) addressed the problems caused by hepatotoxic and neurotoxic cyanobacteria in drinking water, and proposed several protocols and guidelines to cope with this issue (Chorus \& Bartram 1999). Biological survey of freshwater systems (rivers, reservoirs, ponds, and lakes) is a keystone monitoring process, but the identification and quantification of potential toxic cyanobacteria can be time consuming, as it is based on the taxonomic identification of these organisms. Moreover, the knowledge of microscopy and taxonomy required for unambiguous identification is often lacking in most of 
the organisations that are responsible for these surveys. Hence it is of crucial importance to develop tools to make it possible to carry out rapid and reliable screening for potential contaminants in water. Molecular fingerprinting is often proposed as an alternative method for identifying potentially toxic species, but it involves delay, and still calls for discrete sampling of water and skilled personnel to perform the analysis. Consequently, any system that can cope with the constraints associated with water monitoring, such as immediacy of response, low maintenance costs, specificity, sensitivity, ease of handling, and rapidity of interpretation, is bound to be of interest. The in vivo auto-fluorescence characteristic of pigment-containing microorganisms, such as cyanobacteria and microalgae, has long been envisaged as a potential diagnostic signal (e.g. Yentsch \& Yentsch 1979, Yentsch \& Phinney 1985), provided that differences in pigment compositions among these phytoplankters lead to differences in fluorescence patterns. A new multi-wavelength submersible probe (FluoroProbe, bbe-Moldaenke) has recently been made available to scientists (Beutler et al. 2002). We used this tool, after simple reconfiguration, to monitor the dynamics of the deep-living filamentous and toxic cyanobacterium Planktothrix rubescens in Lake Bourget, France, an organism which is responsible for local degeneration of the water supply.

\section{MATERIALS AND METHODS}

Field survey. The survey (including microscopic counting) started in September 1999, after a bloom of Planktothrix rubescens had been detected in Lake Bourget, the largest natural lake in France (for a physical description, see Groleau et al. 2000). The outbreak of the bloom became evident when dead filaments of $P$. rubescens appeared at the outlet from a drinking water plant that processes lake water pumped from a depth of $30 \mathrm{~m}$. From September 2000, the FluoroProbe (see below) was used for depth profiling once or twice a month, from the surface down to $45 \mathrm{~m}$ (which is well below the photic layer), in addition to discrete water sampling for the purposes of cell counting and identification. Water samples were collected at discrete depths, and $125 \mathrm{ml}$ were immediately preserved using Lugol's iodine solution, and kept for further taxonomic analysis and counting using the sedimentation method (Utermöhl 1958). A total of $500 \mathrm{ml}$ were sampled and kept in dark plastic bottles before being filtered through $25 \mathrm{~mm}$ Whatman GF/F glass fibre filters in the laboratory. The filters were frozen at $-30^{\circ} \mathrm{C}$, and then the chlorophyll was extracted using $5 \mathrm{ml}$ of cold acetone:water $(90: 10 \mathrm{v} / \mathrm{v}$ ratio) to permit the spectrophotometric determination of chlorophyll a ( $\mathrm{chl}$ a), according to Strickland \& Parsons (1968).

For a detailed description of FluoroProbe, see Beutler et al. (2002). Briefly, this device is able to discriminate between the main phytoplanktonic groups (i.e. diatoms and dinoflagellates, blue-green algae, green algae, cryptophytes) in mixed populations, on the basis of the relative fluorescence intensity of chl $a$ at $680 \mathrm{~nm}$ (due to the Photosystem II core pigments), following sequential light excitation by 5 light-emitting diodes (LEDs) emitting at 450,525, 570, 590 and $610 \mathrm{~nm}$. Depending on the accessory pigments of the light-harvesting complexes, and thus on the phylogenetic position of the phytoplanktonic individuals present in the sample, a set of characteristic fingerprints can be detected. Dedicated software (FluoroProbe 1.6, bbeMoldaenke) is then used to calculate the relative amount of each algal class that must be present, expressed in terms of the equivalent amount of chl a per liter of water (equiv. $\mu \mathrm{g} \mathrm{chl} \mathrm{al}^{-1}$ ), to account for the recorded fluorescence values. Measurements and calculations were performed every second during the profiling, from the surface to $-45 \mathrm{~m}$, corresponding to an approximate duration of $15 \mathrm{~min}$ with 900 data points for each profile, collected every $5 \mathrm{~cm}$ along the vertical sampling transect.

Calibrating the device using laboratory cultures. Several batch cultures of eukaryotic microalgae (belonging to the algal groups most commonly encountered in Alpine Lakes) and cyanobacteria (Table 1), as well as one strain of Planktothrix rubescens isolated from Lake Bourget (Humbert \& Le Berre 2001), were

Table 1. Cultured phytoplankton and cyanobacteria strains, and their media references

\begin{tabular}{|lccc|}
\hline Group & Species & Medium composition & Source \\
\hline Cyanobacteria & 'Blue greens' Cylindrospermopsis raciborskii & ASM-1 & Gorham et al. (1964) \\
& Red Planktothrix rubescens & Z & Leboulanger et al. (2001) \\
Bacillariophyta & Navicula accomoda & DV & Leboulanger et al. (2001) \\
Chlorophyta & Chlorella vulgaris & L-C & Leboulanger et al. (2001) \\
& Scenedesmus subspicatus & L-C & Leboulanger et al. (2001) \\
Others & Synura petersenii & MWC & Guillard \& Lorenzen (1972) \\
\hline
\end{tabular}


Table 2. Built-in fingerprints $\left(^{*}\right)$ and calculated values of relative fluorescence for each excitation wavelength, for each phytoplankton or cyanobacteria strain tested, and for the Planktothrix rubescens bloom in Lake Bourget (expressed as relative

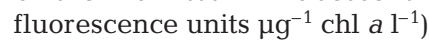

\begin{tabular}{|c|c|c|c|c|c|c|c|c|c|c|}
\hline \multirow{3}{*}{$\begin{array}{l}\lambda_{\mathrm{ex}} \\
(\mathrm{nm})\end{array}$} & \multicolumn{3}{|c|}{ Cyanobacteria } & \multicolumn{2}{|c|}{ - Bacillariophyta- } & \multicolumn{3}{|c|}{ Chlorophyta } & \multicolumn{2}{|c|}{ Others } \\
\hline & - 'Blue- & reens'_— & - Red- & & & & & & & \\
\hline & $\begin{array}{c}\text { Blue- } \\
\text { greens* }\end{array}$ & $\begin{array}{l}\text { C. raci- } \\
\text { borskii }\end{array}$ & $\begin{array}{l}\text { P. rube- } \\
\text { scens }\end{array}$ & Diatoms* & $\begin{array}{l}\text { N. acco- } \\
\text { moda }\end{array}$ & Greens* & $\begin{array}{l}\text { C. vul- } \\
\text { garis }\end{array}$ & $\begin{array}{l}\text { Scenedesmus } \\
\text { spp. }\end{array}$ & $\begin{array}{l}\text { Crypto- } \\
\text { phyceae* }\end{array}$ & $\begin{array}{l}\text { S. peter- } \\
\text { senii }\end{array}$ \\
\hline 450 & 1.47 & 1.09 & 5.96 & 7.33 & 4.36 & 4.37 & 3.93 & 3.19 & 5.42 & 6.48 \\
\hline 525 & 3.81 & 2.46 & 7.48 & 2.55 & 1.77 & 1.53 & 2.04 & 1.56 & 5.62 & 2.05 \\
\hline 570 & 14.51 & 8.96 & 7.19 & 4.32 & 4.20 & 4.26 & 4.15 & 5.25 & 8.26 & 4.72 \\
\hline 590 & 8.41 & 5.38 & 5.86 & 4.08 & 2.50 & 3.43 & 6.91 & 3.20 & 8.56 & 3.11 \\
\hline 610 & 0.76 & 0.75 & 1.99 & 10.68 & 5.67 & 9.09 & 3.93 & 7.63 & 6.48 & 9.26 \\
\hline
\end{tabular}

used to calibrate the probe. The probe was immersed in $4 \mathrm{l}$ of GF/F pre-filtered lake water (providing a 'natural' blank), and the appropriate amounts of the corresponding algal culture were added to a $140 \mathrm{~mm}$ diameter Plexiglas tube to calibrate and define the fingerprints. Mixed cultures were prepared by adding small amounts of $P$. rubescens to a diluted culture (ca. $10 \mu \mathrm{g} \mathrm{chl} \mathrm{a}^{-1}$ ) of species belonging to any of the different spectral groups listed in Table 1, to find out how well the instrument can discriminate the $P$. rubescens signal in the presence of another microalga.

\section{RESULTS}

\section{Fingerprints for Planktothrix rubescens}

The original purchased device was provided with fingerprints for cryptophyceae, diatoms, chlorophyceae, and cyanobacteria only for 'green' species, i.e. phycocyanin (PC)-containing organisms such as Microcystis sp., and not for 'red' cyanobacteria. The raw data provided by the probe at the beginning of the quasi-monospecific bloom described during this study (corresponding to $>95 \%$ of the total biomass) allowed us to calculate the in situ specific fluorescence response of Planktothrix rubescens (Table 2). Because this species has a higher phycoerythrin (PE) content than PC-containing cyanobacteria, the fluorescence yield was increased at the 450 and $525 \mathrm{~nm}$ excitation wavelengths. This was due to the greater absorbance and energy transfer to chl $a_{680}$ at these shorter wavelengths (Downes \& Hall 1998). The fingerprints obtained with the cultured $P$. rubescens strain isolated from Lake Bourget were similar to those obtained by in situ measurements (Table 2), and so only the recorded field signature was used for the subsequent detection of this species in natural waters. These fingerprints allowed the determination and quantification of $P$.

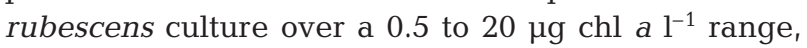

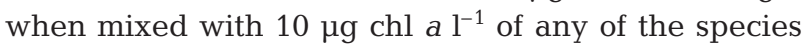
listed in Table 1.

\section{Comparison between the in situ probe signal and the chl a concentrations}

An example of the vertical profiles obtained in the survey is given in Fig. 1. During complete mixing of the lake, Planktothrix rubescens biomass is homogeneous over the vertical, whereas it peaks in summer and autumn generally between 10 and $15 \mathrm{~m}$ depth. Values expressed in

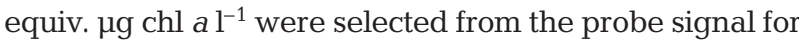
total chl $a$ at the depths corresponding to discrete samples (see above), and plotted against the results of the spectrophotometric analysis for the same samples. A linear correlation was established between these 2 measurements $(y=1.0311 x, r=0.775, p<0.01, n=55$; Fig. 2).
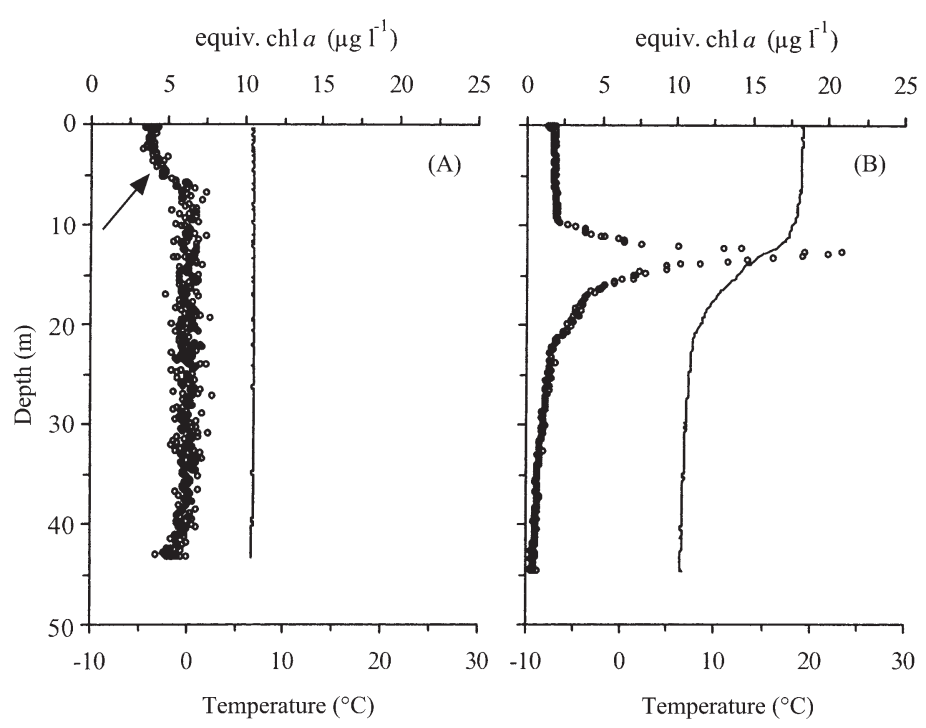

Fig. 1. Typical vertical structure profiles obtained using the FluoroProbe. o: data points for Planktothrix rubescens biomass; line: temperature profile. (A) P. rubescens abundance in winter (January 2001) when water mixing was complete. Arrow indicates the attenuation of the fluorescence signal at shallow depths due to photochemical quenching. (B) $P$. rubescens abundance in summer and autumn (e.g. September 2000) when biomasses are concentrated close to the thermocline, under strong water-stratification 


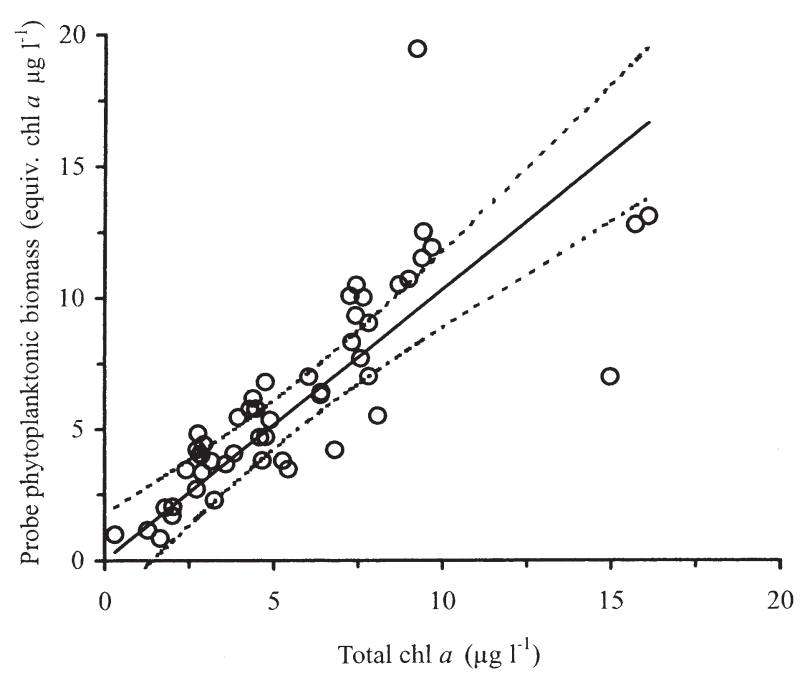

Fig. 2. Calibration curve for the probe response to total chl a signal (all phytoplankton groups) depending on the actual chl a concentrations determined by spectrophotometry of discrete samples $\left(y=1.03 x, r^{2}=0.601, n=55\right)$. Confidence intervals $(95 \%)$ for the regression line are indicated by dashed curves

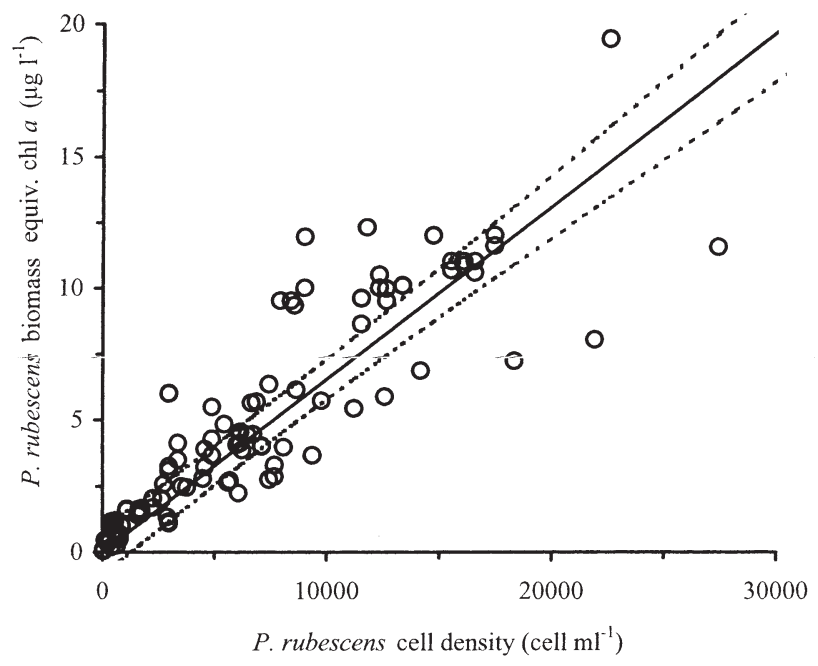

Fig. 3. Calibration curve of the probe response (Planktothrix rubescens signal only) compared to the cell density of the species determined by microscopic counting of discrete samples. $\left(y=0.000654 x, r^{2}=0.806, n=110\right)$ Confidence intervals $(95 \%)$

for the regression lines are indicated by dashed curves
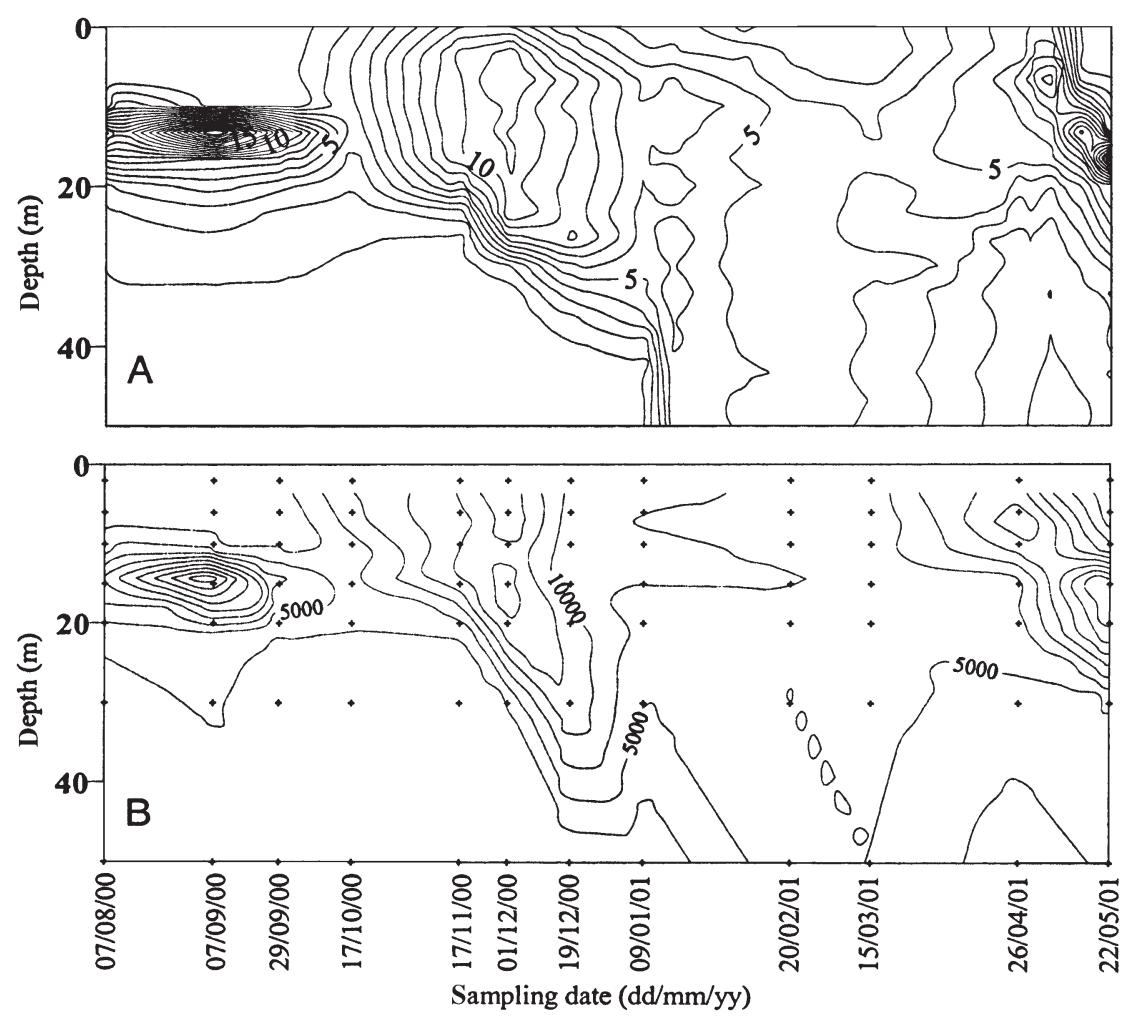

Fig. 4. (A) Spatio-temporal evolution of Planktothrix rubescens biomass during the survey, measured using the fluorescence probe (more than 300 data points for each profile). Values are reported in equiv. chl a $\mathrm{l}^{-1}$; (B) spatiotemporal evolution of $P$. rubescens biomass during the survey, measured by cell counts. +: Discrete samples (10 depths sampled per profile). Values are reported in cells $\mathrm{ml}^{-1}$. Data were fitted using Surfer ${ }^{\circledR} 7.0$ (Golden Software), using the kriging contouring method

\section{Comparison between the in situ probe signal and cell densities}

Values for Planktothrix rubescens,

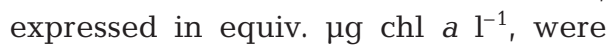
selected from the probe signal, at the depths corresponding to discrete samples, and plotted against the cell counts for the same species in these samples. There was a strong linear correlation between these 2 values $\left(y=6.5410^{-4} x\right.$, $\mathrm{r}=0.898, \mathrm{p}<0.01, \mathrm{n}=110$; Fig. 3 ). It is noteworthy to add that the relationship was not significantly modified when the data obtained at depths of 2 and $6 \mathrm{~m}$ were removed from the data set, to avoid possible fluorescence-quenching errors $\left(y=6.6410^{-4} x, r=0.899, \mathrm{p}<0.01, \mathrm{n}=85\right.$; not shown). This quenching is due to the transfer of energy to the photosynthetic process when the cells are exposed to sunlight and to photoinhibition, thus decreasing the fluorescence yield, e.g. Falkowski \& Raven (1997). It was also noticed during a supplementary study, when the apparent biomass of $P$. rubescens in the top $6 \mathrm{~m}$ of water fell by $>40 \%$ after sunrise, compared to the value detected in the same water body at the end of the previous night (e.g. as in Fig. 1A). 


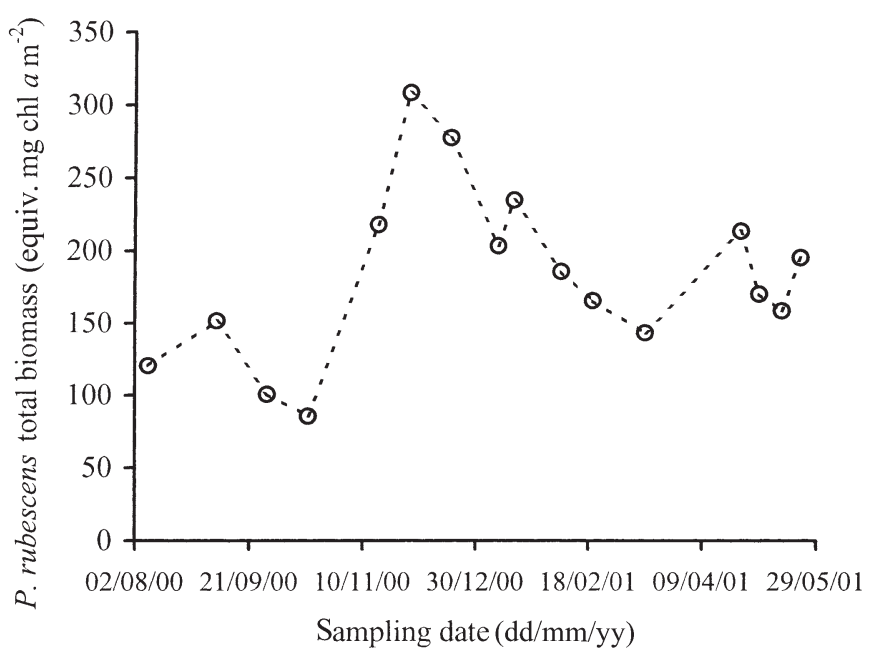

Fig. 5. Change in the total biomass of Planktothrix rubescens (expressed as biomass in equiv. $\mathrm{mg} \mathrm{chl} \mathrm{a} \mathrm{m}^{-2}$ lake surface) integrated over $40 \mathrm{~m}$ below the surface during the survey

\section{Seasonal pattern of the vertical distribution of Planktothrix rubescens}

The annual pattern of change recorded for Planktothrix rubescens during the whole survey was similar, as determined both from the probe fluorescence measurements (Fig. 4A) and from the classical microscopic cell counts (Fig. 4B). The microscopic examination showed clearly that the total phytoplanktonic biomass was strongly dominated by this cyanobacterium (>90\%) for a significant part of the year (Jacquet et al. unpubl. data). The bloom appears in spring as lake thermal stratification occurs, then throughout the summer most of the biomass is concentrated close to the thermocline (Fig. 1A), between 10 and $15 \mathrm{~m}$ in depth. In fall, as the thermocline starts to erode, and the mixed layer expands in response to a decrease in temperatures and wind stress effect, the peak $P$. rubescens biomass spreads over the whole top layer. In late fall, the thermal stratification breaks down completely, and the filaments of $P$. rubescens are found evenly distributed from the surface down to the bottom of the lake (Fig 1B). The mean total biomass of the cyanobacterium, integrated over the top $40 \mathrm{~m}$ of water, ranged from 100 to 150 equiv. $\mathrm{mg} \mathrm{chl} \mathrm{a} \mathrm{m}{ }^{-2}$ from August 2000 to mid-October, then increased to more than 300 equiv. $\mathrm{mg}$ chl $a \mathrm{~m}^{-2}$ in early December, before starting to fall again in winter and spring (Fig. 5). Such high concentrations of $P$. rubescens may pose a severe threat to water supplies, as the main inlets for water pumping are located at depths of between 30 and $40 \mathrm{~m}$ in Lake Bourget, and we assume that the toxic content is directly linked to the total biomass of the cyanobacterium. Other phytoplanktonic groups were found abundant on discrete dates, but these have had no significant influence on the level of confidence for $P$. rubescens determinations. An example is given in Fig. 6, where most of the phytoplanktonic biomass is dominated by green microalgae above $10 \mathrm{~m}$ depth, topping the $P$. rubescens peak located at $13 \mathrm{~m}$.

\section{DISCUSSION}

\section{Threats caused by the Planktothrix rubescens bloom}

In Lake Bourget, Planktothrix rubescens has continuously been recorded in the water column since the beginning of this study, and a monitoring program will carry on for the next $2 \mathrm{yr}$. As this species had already been demonstrated to be hepatotoxic (Humbert et al. 2001), it is carefully monitored to provide a reliable alert system for water producers and local authorities. This phenomenon has already been reported, for example, in a smaller Alpine Lake (Lake Nantua, France), where $P$. rubescens was recorded during a 9 yr survey. After a nutrient loading reduction program, based on a scientific study, a partial recovery was achieved, and the cyanobacterial biomass in the top layer of the lake

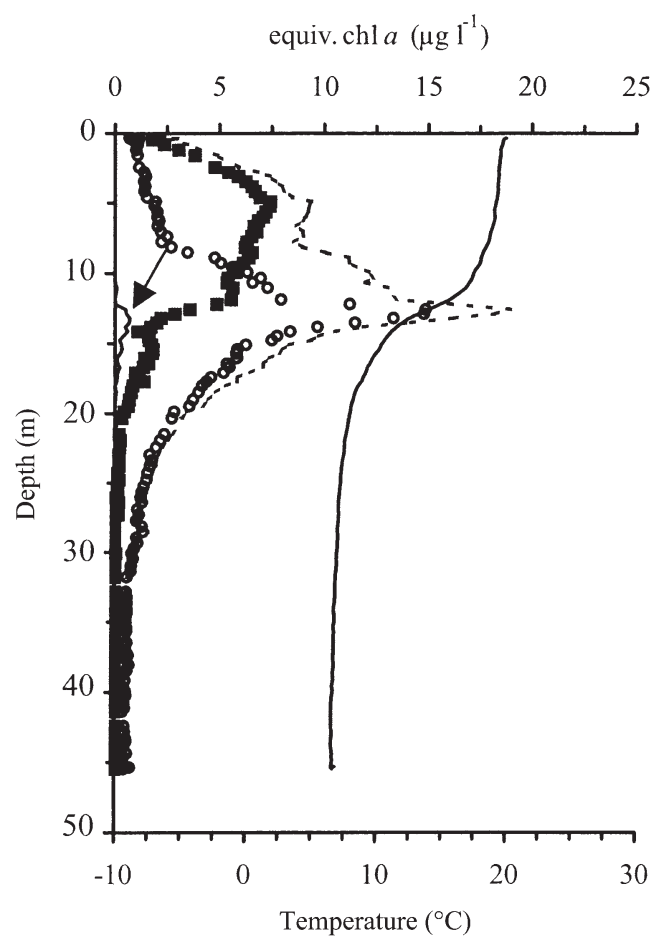

Fig. 6. Example of discrimination between chlorophyceae (घ), 'blue-green' cyanobacteria (genus Pseudanabaena, bold line marked with arrow) and Planktothrix rubescens (ㅇ) obtained from Lake Bourget on August 8, 2000. Total chl $a$ is indicated by dashed line, temperature profile is indicated by bold line on right 
decreased (Feuillade 1994). These human threats gain importance as soon as the biomass sinks to the depth from which water is being pumped, and they may also cause damage to wildlife (mainly fish and waterfowl). With regard to fish, the only influencing parameter is the depth of the thermocline driving the mixing of the biomass, whereas with regard to waterfowl, it depends on the capacity of various trophic levels to accumulate the toxin to the final consumers. So far there has been no evidence of fish or bird kills in Lake Bourget linked to $P$. rubescens toxicity.

\section{Use of FluoroProbe for indirect monitoring of microcystin}

Provided that the species which is suspected of being responsible for the problem has already been identified (as in this case), it appears that it would be very easy to carry out a water quality survey using the FluoroProbe. As we have demonstrated, the system offers a fast and reliable means of following the spatio-temporal evolution of the cyanobacterium Planktothrix rubescens. It requires only basic training, and calls for much less time and skill than is required for microscopic identification and counting. One of its major advantages over discrete sampling arises from the high resolution of the system, which can be very strong along the vertical axis (see Fig. 1). One can see that when the cells are peaking close to the thermocline, a sampling bottle becomes an inefficient way of detecting the maximum density of the organisms, because of the thickness of the layer where they are concentrated.

The FluoroProbe system is limited in the number of algal groups that can be accounted for, practically 4 or 5 groups can be measured simultaneously. We did not test the accuracy for the other groups that we have encountered during this study, but we observed no significant changes in the determination of Planktothrix rubescens depending on the presence or absence of diatoms, for example, green microalgae. Moreover, we were able to follow quantitatively the co-occurrence of small populations of blue-green cyanobacteria together with the reddish one, as shown in Fig. 6. These 2 groups are very different in their fingerprints, but such a precision seems unachievable for the diatomcryptophyceae pair for example.

The in vivo fluorescence signal is modified depending on the physiological state of the phytoplankton cells that are followed; in this precise case it seems not to impair the accurate survey of Planktothrix rubescens for monitoring purposes. Fine-scale studies of the dynamics of this species in the sub-surface waters, if proven useful, should therefore require night measuring to compensate for this problem.

\section{CONCLUSION}

The FluoroProbe provides an efficient tool for studying the population dynamics of Planktothrix rubescens in lake water. The data provided by this device correlate closely with data obtained by microscopic counts, enabling us to envisage future use of the FluoroProbe as an alternative to the fastidious methods of species identification and counting, and also to provide a warning system when toxin-producing cyanobacteria are detected. Several other types of studies could also be performed using this device, for example, determinations of the population dynamics of various phytoplankton groups, which can take advantage of the numerous data generated by this system, and of the vertical resolution that it provides. By way of example, we have already monitored the development of another cyanobacterium, Microcystis aeruginosa, in a reservoir where it exhibited diurnal vertical migration (data not shown). However, it is noteworthy to add that some points remain to be addressed, such as, for example, the quenching of fluorescence in the top surface layer, which can decrease the fluorescence yield of a given population by almost $40 \%$. Other caveats can arise if the planktonic biomass is so high that light (at the excitation or emission wavelength) is unable to penetrate water. This dramatically restricts the usefulness of the system, as we experienced in fishery ponds, where the cyanobacterial biomass exceeded $500 \mathrm{\mu g} \mathrm{l}^{-1}$ (data not shown).

In conclusion, this system is very versatile and easy to use under field conditions, and these properties make it suitable for monitoring purposes, provided that adequate calibrations are made prior to routine measurements. As water resources become increasingly scarce and vulnerable, such a device, which combines scientific reliability and a realistic approach to safety, could be helpful for setting up early alert procedures. Thus, we have developed a monitoring framework intended to help the local authorities manage the problems caused by Planktothrix rubescens, and this system is now effective and has been validated for the next 4 yr.

Acknowledgements. This study was supported by grants from the Environment and Health Program, held by the French Ministry of Environment (MATE, Contract EN00C06). Anonymous reviewers are acknowledged for improvements to this manuscript.

\section{LITERATURE CITED}

Beutler M, Wiltshire KH, Meyer B, Moldaenke C, Lüring C, Meyerhöfer M, Hansen UP, Dau H (2002) A fluorometric method for the differentiation of algal populations in vivo and in situ. Photosynth Res 72:39-53 
Bright DI, Walsby AE (2000) The daily integral of growth by Planktothrix rubescens calculated from growth rate in culture and irradiance in Lake Zürich. New Phytol 146: 301-316

Burkholder JM, Noga EJ, Hobbs CH, Glasgow HB (1992) New 'phantom' dinoflagellate is the causative agent of major estuarine fish kills. Nature 358:407-410

Chorus I, Bartram J (1999) Toxic cyanobacteria in water. Spon E \& FN. World Health Organization, London

Downes MT, Hall JA (1998) A sensitive technique for the measurement of phycobilin pigments and its application to the study of marine and freshwater picophytoplankton in oligotrophic environments. J Appl Phycol 10: 357-363

Falconer IR (1999) An overview of problems caused by toxic blue-green algae (Cyanobacteria) in drinking and recreational water. Environ Toxicol 14:5-12

Falkowski PG, Raven JA (1997) Aquatic photosynthesis. Blackwell Science, Malden, MA

Feuillade J (1994) The cyanobacterium (blue-green algae) Oscillatoria rubescens D.C. Arch Hydrobiol Beih Ergebn Limnol 41:77-93

Gorham PR, McLachlan J, Hammer U, Kim WK (1964) Isolation and culture of toxic strains of Anabaena flos-aquae (Lyngb.) de Bréb. Verh Int Verein Limnol Theor Angew Limnol 15:796-804

Groleau A, Sarazin G, Vinçon-Leite B, Tassin B, QuiblierLlobéras C (2000) Tracing calcite precipitation with specific conductance in a hard water Alpine Lake (Lake Bourget). Water Res 34:4151-4160

Editorial responsibility: William $\mathrm{Li}$,

Dartmouth, Nova Scotia, Canada
Guillard RRL, Lorenzen CJ (1972) Yellow-green algae with chlorophyllide $C$. J Phycol 8:10-14

Humbert JF, Le Berre B (2001) Genetic diversity in 2 species of freshwater cyanobacteria, Planktothrix (Oscillatoria) rubescens and P. agardhii. Arch Hydrobiol 150:197-206

Humbert JF, Paolini G, Le Berre B (2001) Monitoring a cyanobacterial bloom and its consequences for water quality. In: Hallegraeff G et al. (eds) Harmful algal bloom 2000. Intergovernmental Oceanographic Commission of UNESCO, p 496-499

Leboulanger C, Rimet F, Hème de Lacotte M, Bérard A (2001) Effects of atrazine and nicosulfuron on freshwater microalgae. Environ Internat 26:131-135

Mez K, Beattie KA, Codd GA, Hanselmann K, Hauser B, Naegeli H, Preisig HR (1997) Identification of a microcystin in benthic cyanobacteria linked to cattle deaths on alpine pastures in Switzerland. Eur J Phycol 32:11-117

Strickland JDH, Parsons TR (1968) Pigment analysis - a practical handbook of seawater analysis. Bull Fish Res Board Can 167:185-205

Utermöhl H (1958) Zur Vervollkommnung der quantitatives Phytoplankton Methodik. Mitt int Theor Angew Limnol 9: 1-38

Yentsch CS, Phinney DA (1985) Spectral fluorescence: an ataxonomic tool for studying the structure of phytoplankton populations. J Plankton Res 7:617-632

Yentsch CS, Yentsch CM (1979) Fluorescence spectral signatures: the characterization of phytoplankton populations by the use of excitation and emission spectra. J Mar Res $37: 471-483$

Submitted: March 4, 2002; Accepted: June 27, 2002

Proofs received from author(s): October 18, 2002 